\title{
Dry Sliding Wear Behavior of Austenitic Stainless Steel Material by Gas Nitriding Process
}

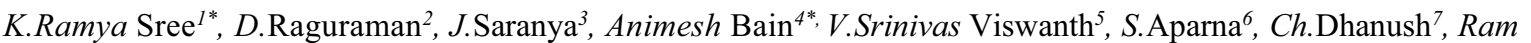 \\ Subbiah $^{6^{*}}$ \\ ${ }^{1}$ Research Scholar, Singhania University, Jhunjhunu, Rajasthan 333515, India \\ ${ }^{2}$ Faculty, Centre for Materials Engineering and Regenerative Medicine, Bharath Institute of Higher Education and Research, Chennai, \\ Tamilnadu 600126, India. \\ ${ }^{3}$ Faculty, Basic sciences \& Humanities, Gokaraju Rangaraju Institute of Engineering and Technology, Hyderabad 500090, India \\ ${ }^{4}$ PG Student, Design for Manufacturing, Gokaraju Rangaraju Institute of Engineering and Technology, Hyderabad 500090, India \\ ${ }^{5}$ Faculty, Mechanical Engineering, Aditya Engineering College, Andhra Pradesh 533437, India \\ ${ }^{6}$ Faculty, Mechanical Engineering, Gokaraju Rangaraju Institute of Engineering and Technology, Hyderabad 500090, India \\ ${ }^{7}$ UG Student, Design for Manufacturing, Gokaraju Rangaraju Institute of Engineering and Technology, Hyderabad 500090, India
}

\begin{abstract}
In industries, components must operate under extreme conditions such as high load, speed, temperature and chemical environment. Materials are selected according to commercial availability, cost and their properties such as strength, hardness, etc. AISI 904L is a high-alloy stainless steel with low carbon content, poor surface hardness and wear characteristics. Many engineering failures are caused by fatigue, corrosion, and poor wear resistance, begins at the surface level. This causes cracks in the surface, reducing the material's life. The surfaces of the materials were subjected to severe thermal, chemical, and shock loads. The selected AISI 904L materials for this work were subjected to gas nitriding process and processed with 3 different time parameters such as 12 hours, 18 hours and 24 hours respectively and named as GN1, $\mathrm{GN} 2$ and GN3. The treatments were done at a constant temperature of $650^{\circ} \mathrm{C}$. Gas nitriding, in comparison to other nitriding processes such as plasma and liquid nitriding, provides good dimensional stability, reduced deformation, and uniform case depth regardless of the size and shape of the specimen. To analyze the wear properties, a pin on a disc machine is used. Finally, metallographic studies were performed by scanning electron microscopy.
\end{abstract}

\section{Introduction}

Stainless steel is a stylish material. They were first made available to industries; their usage has continued to expand into new areas. To successfully make use of stainless steels in application were wear resistant is highly needed, it is necessary to know their properties related to hardness, surface quality, wear and corrosion resistance [1-3]. Stainless steels are being used for both corrosion and resistance to high temperature applications. Stainless steels being known for better corrosion resistance and less maintenance, relatively cost-effective makes it the ideal base material for many commercial applications. The use of stainless steel compares to carbon steel shows development, in contrast to structural steels and their properties in many applications [4-6].

Stainless steel is $100 \%$ reusable and recyclable. In fact, more than $70 \%$ new products from stainless steel are produced from re-melted worn out material, which makes it environment friendly material [7-10]. AISI 904L stainless steel can be used at extreme temperatures application and enhance their properties with dimensional stability. To use this 904L stainless steel successfully for applications related to wear resistance and high temperature usage, its mechanical properties need to be enhanced with dimensional stability [16-20]. AISI 904L were preferred heat resistance and corrosive resistance applications. Formation of austenite is made by stable austenitizing elements such as manganese and nickel etc. These steels retain the structure of austenite at ambient temperature [11-15].

Austenitic stainless steels are practically nonmagnetic when annealed and can only be hardened through cold working. The features of ferromagnetism were noticed during cold working process. They usually have reasonable cryogenic and excessive temperature properties in improving the wear. The chromium content is 17.5 to $25 \%$ and $\mathrm{Ni}$ is less than $35 \%$ [21-23]. Typical applications for a range of brands include tanks, storage tanks and piping for corrosive liquids, furnace parts, catalytic converter parts, containers, heaters, expansion joints and bellows. Enormous chromium content contributes to first-class wear improvement on austenitic stainless steel, making it applicable for nuclear power plants and submarines [22-25].

\footnotetext{
* Corresponding author: author@e-mail.org
} 


\section{Experimental procedure}

\subsection{Material Composition}

For this research work, AISI $904 \mathrm{~L}$ is chosen and the composition are $0.03 \%-\mathrm{C}, 2.1 \%-\mathrm{Mn} .1 .1 \%-\mathrm{Si}, 0.03 \%$-P, $18.2 \%-\mathrm{Cr}, 0.02 \%-\mathrm{S}, 22.5 \%-\mathrm{Ni}, 3.2 \%-\mathrm{Mb}$, Remaining Fe. The specimens were taken in the form of circular pins and a disc. The dimension of the pin was found to be $35 \mathrm{~mm}$ length, $8 \mathrm{~mm}$ diameter treated to $12 \mathrm{hrs}, 18$ hrs and $24 \mathrm{hrs}$. Disc dimension was found to be $120 \mathrm{~mm}$ diameter, $8 \mathrm{~mm}$ thick treated to saturated level. The samples of were treated with plasma nitriding process. Samples were disc polished, etched with sulphuric acid for 15 minutes and dried prior to wear testing.

\subsection{Wear Test}

The specimens were gas nitride and carried out in a belltype furnace to 12 hours, 18 hours and 24 hours, respectively as shown in the Fig 1. Using a pin on disc apparatus as shown in Fig 2, with the test pin rotating at $1250 \mathrm{rpm}$, with a constant load of $20 \mathrm{~N}$ for time period of 3 minutes, the wear test were performed. The wear loss and wear rate were determined.

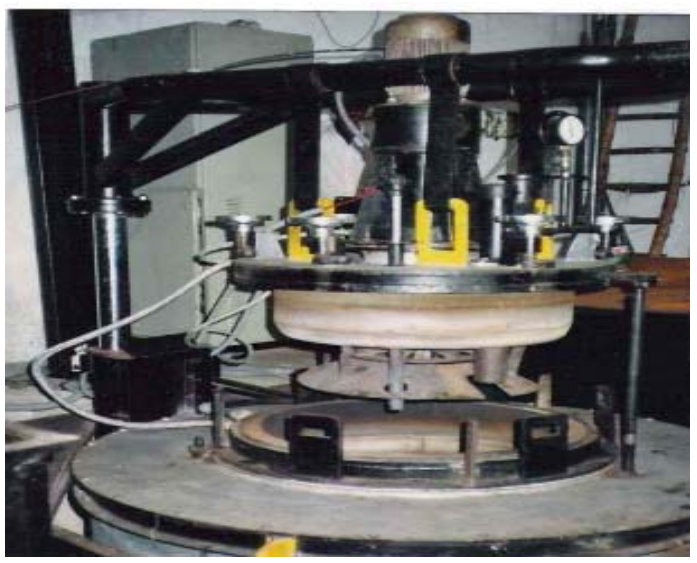

Fig.1. Gas Nitriding Equipment used for Experimentation

The flow rate of ammonia gas was maintained at 7 $\mathrm{m} 3 / \mathrm{hr}$. The tendancy to form white layer decreases with increasing dissociation of ammonia in the range of 25$35 \%$, whereas much higher dissociation results in non uniformity of gas composition within the furnace and hence an optimal dissociation range of $45-60 \%$ was employed. A net weight of $400 \mathrm{gms}$ of ammonium chloride was used for every cycle of nitriding. After nitriding, the specimens were cooled for about 30 minutes.

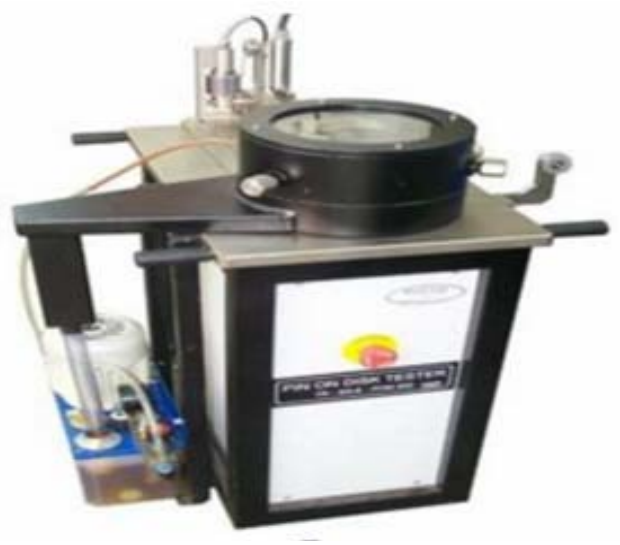

Fig.2. Pin on Disc Machine

\section{Results and Discussions}

Fig.3 shows the microstructure of Untreated AISI 904L specimen when magnified under scanning electron microscope. The peels of material were high, as the untreated specimen was subjected to load of $20 \mathrm{~N}$. As the untreated specimen was found to be high ductile in nature, some cracks were noted on the surface. No case depth was noticed, the volume wear loss was noticed to be $8.26 \times 10^{-4} \mathrm{~cm}^{3}$, the hardness was found to be $335 \mathrm{H}_{\mathrm{V}}$.

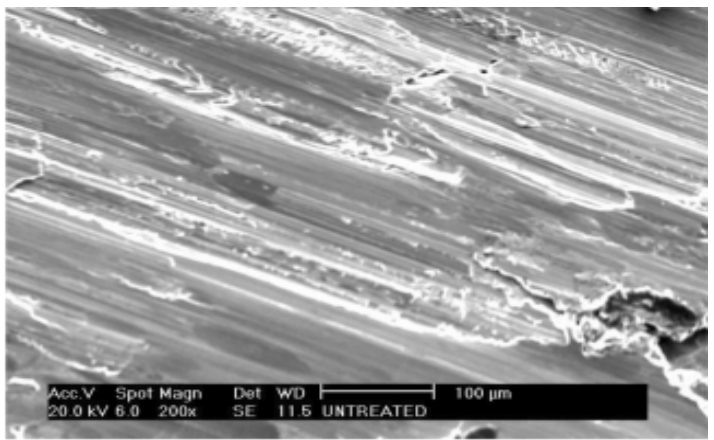

Fig.3. SEM image of untreated AISI904L specimen

Fig.4 shows the microstructure of specimen when subjected to 12 hours of treatment. Chromium nitride and iron nitride diffusion were deposited on the surface level. An expanded austenite layer with $14 \mu \mathrm{m}$ as case depth and an average hardness of about $715 \mathrm{Hv}$ were obtained. The diffusion process were based upon the nitrogen solubility. The solubility limit of nitrogen in iron is temperature dependant between $540^{\circ} \mathrm{C}$ to $680^{\circ} \mathrm{C}$, which is below the austenitic formation temperature. Due to this, gas nitriding specimens have minimum distortion and excellent control in resisting the wear. The volume wear loss were found to be $7.11 \times 10^{-4} \mathrm{~cm}^{3}$. 


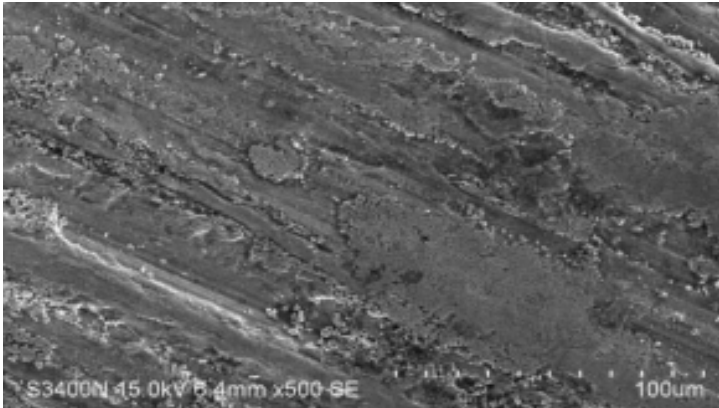

Fig.4. SEM image of gas nitrided specimen for $12 \mathrm{hrs}$

The more important effect of nitriding is the ability to form hard compounds with iron. These compounds can give rise to the surface hardness as maximum as possible. The quick diffusion forms hard complex iron nitrides dispersed to the greater depths. Since nitride forming elements have a greater affinity for nitrogen they prevent the diffusion to a greater depth giving an extremely hard but shallow case. Through this gas nitriding process, the specimen which was subjected to 18 hrs as shown in Fig 5 confers both wear resistance and fatigue resistance on turbine blades. A Case depth of $17.5 \mu \mathrm{m}$ was obtained with a volume wear loss was found to be $6.4 \times 10^{-4} \mathrm{~cm}^{3}$ and hardness of $719 \mathrm{Hv}$.

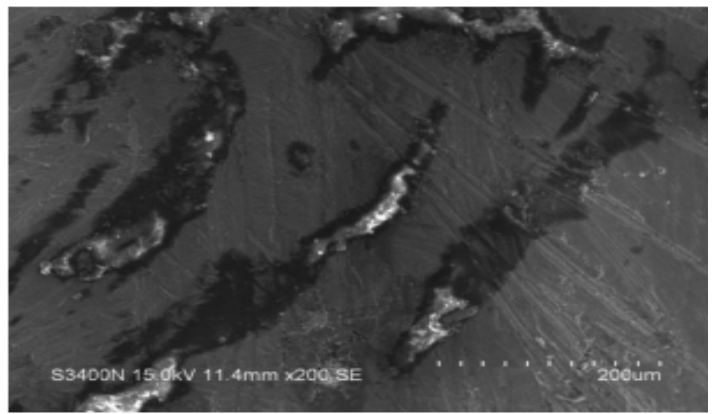

Fig.5. SEM image of gas nitrided specimen for $18 \mathrm{hrs}$

As the time of treatment increases, the nucleation growth will eventually become as compound layer. This layer is generally hard and brittle. It consists of two intermixed phases containing $\mathrm{Fe}_{3} \mathrm{~N}$ and $\mathrm{Fe}_{4} \mathrm{~N}$. This layer doesn't diffuse into the steel, but stays on the intermediate surface and grows dense with temperature, gas proportion and time. The layer beneath the compound zone is called as diffusion zone. The zone is made up with hard nitrides formed during nitridning, with presence of alloying elements such as $\mathrm{Cr}$, Mo and V.

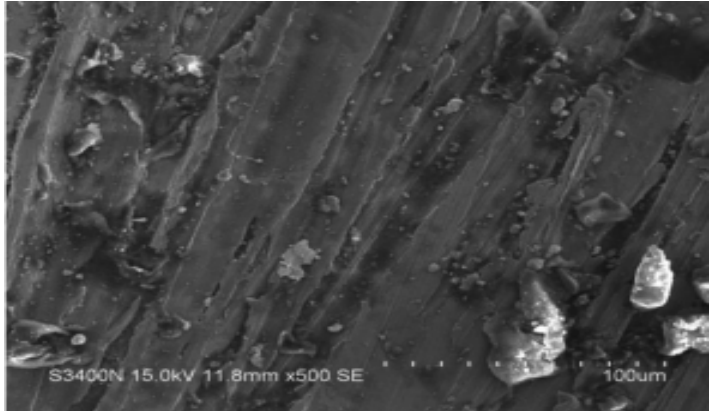

Fig.6. SEM image of gas nitrided specimen for $24 \mathrm{hrs}$

In Fig 6, it was observed that, AISI 904L stainless steel was modified with gas nitriding with low deformation when treated with constant temperature. The end results showed that the effect of phase composition and the micro hardness profile of the nitrided layers were enhanced. Fig.6 showed the enhanced austenite section revealing out the formation of chromium nitride phase. The case depths of the nitrided layers were increased with respect to time. The values of hardness were found to be $729 \mathrm{H}_{\mathrm{v}}$, volume wear loss of $8.7 \times 10^{-4} \mathrm{~cm}^{3}$ and the case depth was noted to be $21 \mu \mathrm{m}$.

\section{Conclusion}

Many research efforts were focused on the development of austenitic stainless steel material. But few people have reported on AISI $904 \mathrm{~L}$ stainless steel materials. One of the best quality surface treatment processes is low temperature gas nitriding which can be used to increase the wear resistance of austenitic stainless steel. AISI 904L have been investigated by gas nitriding process through this present work. The hardness of the material was increased from $715 \mathrm{H}_{\mathrm{V}}$ to $729 \mathrm{H}_{\mathrm{V}}$ compared with untreated sample. The volume wear losses were varying from $8.26 \times 10^{-4} \mathrm{~cm}^{3}$ to $8.7 \times 10^{-4} \mathrm{~cm}^{3}$. The expanded austenite layer was surface molded in thickness from 2 to 27 microns. The predetermined rate of dissociation of ammonia has influenced the nitrided specimens wear resistance. It was found that the wear resistance of the nitrided specimens formed a non-dispersive hardened layer on the austenite surface

\section{References}

1. C.H. Hsu, C.K. Lin, K.H. Huang, K.L. Surf Coat and Tech.J.E 88, 101 (2012).

2. C. Zhao, C.X. Li, H. Dong, T. Bell, Surf Coat and Tech.J.E 201, 2109 (2006).

3. C.Z. Christiansen Thomas, A.J. Marcel, Somers, Surface Engineering. J.E 9, 82 (2006).

4. Ghorabaei AS, Banadkouki SSG.Mater Sci Eng. J.E 73, (2017).

5. Bobadilla M, Tschiptschin A. Mater Res. J.E 4, 390 (2015).

6. C. Arlos Mario Garzon, H. Thomas, J. Francisco Dosantos, Wear.J.E 259, 145 (2005). 
7. M.Mamatha Gandhi, Animesh Bain, $\mathrm{P}$ Rohith, R. Srilatha, Ram Subbiah, E3S Web of Conferences, 184, 01002, (2020)

8. K. Ramya Sree, G. Keerthi Reddy, K. Aishwarya, E. Nirmala Devi, Ram. Subbiah, E3S Web of Conferences 184, 01003 (2020)

9. A Rohit Sai Krishna, B Vamshi Krishna, D Harshith, T Sashank, Ram Subbiah, E3S Web of Conferences 184, 01018 (2020)

10. Shivani Koppula, Aakula Rajkumar, Siram Hari Krishna, Reddi Sai Prudhvi, S. Aparna,Ram Subbiah, E3S Web of Conferences 184, 01019 (2020)

11. Lakshmi Deepak Tadepalli, Ananda Mithra Gosala, Lokesh Kondamuru, Sai Chandra Bairi, A. Anitha Lakshmi, Ram Subbiah, E3S Web of Conferences 184, 01020 (2020)

12. Gandla Lakshmi Prasanna, G. Keerthi Reddy' Ram Subbiah, E3S Web of Conferences 184, 01021 (2020)

13. Gandla Lakshmi Prasanna, J Saranya, Ram Subbiah, E3S Web of Conferences 184, 01022 (2020)

14. Manne Vamshi, J. Saranya, Ram Subbiah, E3S Web of Conferences 184, 01023 (2020)

15. ManneVamshi, AnimeshBain, M. Sreekanth, Ram Subbiah, E3S Web of Conferences 184, 01024 (2020)

16. Ram.Subbiah, Md.Rahel, A.Sravika R.Ambika, A.Srujana, E.Navya, Materials Today: Proceedings, 18, (7), 2265-2269, (2019)

17. A. Rohit Sai Krishna, B. Vamshi Krishna, T. Sashank, D. Harshith, Ram Subbiah, Materials Today: Proceedings. 27 (2) 1555-1558 (2020)

18. K. Manjith Srinivas, S. Bharath, P. N. V. Krishna Chaitanya, M. Pramod, Ram Subbiah, Materials Today: Proceedings. 27 (2), PP 1575-1578 (2020)

19. B.Chaitanya kumar, P.Sri Charan, Kanishkar Jayakumar, D.Alankrutha, G.Sindhu, Ram

Subbiah, Materials Today: Proceedings. 27 (2), 1541-1544 (2020)

20. T. Lakshmi Deepak, G. Ananda Mithra, K. Lokesh, B. Sai Chandra, Ram Subbiah, Materials Today: Proceedings. 27(2)1681-1684 (2020)

21. Nirmala Devi, G.Chitra.S, Selvasekarapandian.S. Premalatha, M. Monisha, S. Saranya.J, Ionics.J.E 23, 2337 (2017)

22. Patel.S, Rana.R.S, Singh.S.K, Study on mechanical properties of environment friendly Aluminium Ewaste Composite with Fly ash and E-glass fiber (Materials Today: Proceedings, Hyderabad, 2017)

23. Prasad.K.S, Gupta.A.K, Singh.Y, Singh.S.K, Materi Eng and Perform.J.E 25, 5411 (2016)

24. Ganesh.R, Subbiah.R, Chandrasekaran.K, Dry Sliding Wear Behavior of Powder Metallurgy Aluminium Matrix Composite (Materials Today: Proceedings, Hyderabad, 2015)

25. Dhanalaxmi.B, Apparao Naidu.G, Anuradha, K, Adaptive PSO based association rule mining technique for software defect classification using $A N N$ (Procedia Computer Science, Hyderabad, 2015) 